\title{
DINÂMICA DA PRODUÇÃO SILVICULTURAL EM MUNICÍPIOS DA MICRORREGIÃO DE TRÊS LAGOAS, MATO GROSSO DO SUL
}

\author{
João Henrique de Souza Barros ${ }^{1}$ \\ Paula Martin de Moraes $^{2}$ \\ Cristiano Marcelo Espínola Carvalho ${ }^{3}$ \\ Leandro Skowronski ${ }^{4}$ \\ Heitor Romero Marques 5 \\ Michel Constantino ${ }^{6}$ \\ Reginaldo Brito da Costa ${ }^{7}$
}

\section{INTRODUÇÃO}

A política de expansão da fronteira agrícola criada pelo governo federal na década de 1970 tinha como pressuposto a ampliação e diversificação da economia nacional, tendo como consequência, a ocupação de áreas do Cerrado para a produção de grãos e estabelecimento de pastagens, potencializando novas fronteiras de produção.

1 Autor correspondente. Doutorando do Programa de Mestrado e Doutorado em Ciências Ambientais e Sustentabilidade Agropecuária. Universidade Católica Dom Bosco (UCDB). E-mails: barros.jhs@gmail.com / ra829833@ucdb.br

2 Doutorado em Biologia Geral e Aplicada. Programa de Mestrado e Doutorado em Desenvolvimento Local. Universidade Católica Dom Bosco (UCDB). E-mail: paulamartin. bio@gmail.com

3 Doutorado em Biologia Celular e Molecular. Docente dos Programas de Mestrado e Doutorado em Ciências Ambientais e Sustentabilidade Agropecuária e em Biotecnologia. Universidade Católica Dom Bosco. E-mail: cristiano@ucdb.br

4 Doutorando do Programa de Mestrado e Doutorado em Ciências Ambientais e Sustentabilidade Agropecuária. Universidade Católica Dom Bosco (UCDB). E-mail: Isk@ucdb.br

5 Doutorado em Desarrollo Local y Planteamiento Territorial. Docente do Programa de Mestrado e Doutorado em Desenvolvimento Local. Universidade Católica Dom Bosco (UCDB). E-mail: heiroma@ucdb.br

6 Doutorado em Economia. Docente dos Programas de Mestrado e Doutorado em Ciências Ambientais e Sustentabilidade Agropecuária e em Desenvolvimento Local. Universidade Católica Dom Bosco (UCDB). E-mail: michel@ucdb.br

7 Doutorado em Ciências Florestais. Docente dos Programas de Mestrado e Doutorado em Ciências Ambientais e Sustentabilidade Agropecuária e em Desenvolvimento Local. Universidade Católica Dom Bosco (UCDB). E-mail: reg.brito.costa@gmail.com 
Com o passar dos anos, as mudanças nas políticas que conduzem a produção agropecuária brasileira fomentaram alterações na dinâmica do uso e ocupação do solo. No estado de Mato Grosso do Sul (MS), o impacto sobre essa dinâmica é notado principalmente no desenvolvimento da silvicultura, impulsionada pelo estabelecimento de grandes maciços florestais de espécies exóticas, sobretudo as do gênero Eucalyptus spp. na região leste do estado.

A silvicultura, como atividade de cultivo florestal, fornece produtos madeireiros e não madeireiros, que podem ou não ter o intuito comercial. Em MS, os principais produtos madeireiros são carvão vegetal, lenha e madeira em tora, e os não madeireiros, folhas de eucalipto e resina (IBGE, 2016). Esses produtos, originários em sua maior parte dos monocultivos de Eucalyptus spp., tem como principal destino a cadeia produtiva do setor florestal. Esta é uma atividade econômica diversificada e complexa, com aplicações energéticas e industriais que transformam e transferem os diversos insumos, desde a pré-produção, até o consumo final de um bem ou serviço, seja no mercado interno ou externo (SNIF, 2017).

As políticas de estímulo ao plantio de florestas de Pinus spp. e Eucalyptus spp. a partir da década de 1960 serviu como combustível para o setor florestal. Ao longo das décadas, diversos incentivos foram concedidos pelos diferentes governos e, no ano 2000, com a criação do Programa Nacional de Florestas, novamente são estabelecidas políticas governamentais para o aumento das áreas plantadas. Tais estratégias estariam alinhadas com a desejável fixação do carbono atmosférico, de conformidade com as exigências globais impostas para a diminuição da emissão de carbono e de gases do efeito estufa (MOSCA, 2008).

As chamadas 'florestas plantadas' tem como objetivo primordial a produção de madeiras para uso industrial através do cultivo e manejo de determinadas espécies de árvores, gerando produtos madeireiros e não madeireiros, além dos bens e serviços decorrentes da utilização direta ou indireta da própria madeira (ORTIGOZA \& SENNA, 2016).

De acordo com a Associação Sul-Mato-Grossense de Produtores e Consumidores de Florestas Plantadas (REFLORE-MS), no período registrado de 2006 a 2012, houve um aumento de $338 \%$ da área total de florestas plantadas no estado. Se considerarmos 
apenas as áreas com espécies do gênero Eucalyptus, o aumento no mesmo período foi de $492 \%$ e, até 2020 , há previsões que será possível chegar a um milhão de hectares plantados (REFLORE-MS, 2013).

Dados da Associação Brasileira de Produtores de Florestas Plantadas (ABRAF, 2013) revelam que a área com espécies de Pinus tem diminuído ao longo dos anos em MS. Essa diminuição está vinculada ao direcionamento da cadeia produtiva da madeira para o atendimento das indústrias de papel e celulose, cuja demanda é por espécies do gênero Eucalyptus.

Para Fonseca \& Thomaz Junior (2014), o aumento da eucaliptocultura em Mato Grosso do Sul - que impulsionou o setor silvicultural no leste do estado - está diretamente ligado à instalação e ampliação de plantas fabris de papel e celulose no município de Três Lagoas. Segundo os autores, um fator preponderante para a vinda de tais empreendimentos para o estado foi a inexistência de movimentos sociais de grande expressão dedicados à luta pela terra. Assim, empresas instaladas em estados com mais conflitos pela terra, como no Espírito Santo e Rio Grande do Sul, tiveram que buscar novas áreas de expansão em outros estados (Mato Grosso do Sul, Tocantins, Maranhão, Piauí e Bahia) onde os movimentos sociais contra o monocultivo de eucalipto ainda não estejam bem organizados.

O notável desenvolvimento da silvicultura nos municípios da microrregião de Três Lagoas foi promovido por um conjunto de fatores, tais como: baixo valor relativo das terras; boa disponibilidade de recursos hídricos; topografia ideal; proximidade da rodovia BR-262, que possibilita o escoamento da produção da madeira e seus subprodutos a outros estados; e perspectiva de atender a indústria local de celulose (CHAEBO et al., 2010).

Em 2009, foi lançado o Plano Estadual para o Desenvolvimento Sustentável de Florestas Plantadas em Mato Grosso do Sul, que destacou potencialidades florestais do estado, como: relevo, clima, estrutura fundiária, flexibilização do licenciamento ambiental para plantios florestais em áreas de pastagem, linhas de crédito e financiamentos, disponibilidade de energia elétrica e gás, hidrovias navegáveis, posição estratégica em relação aos mercados consumidores, dentre outras (Mato Grosso do Sul, 2009). 
Fagundes \& Schmidt (2011) destacam pontos negativos importantes do sistema agroindustrial da silvicultura em Mato Grosso do Sul. Para as autoras, o principal entrave para o maior desenvolvimento do sistema está ligado às questões de infraestrutura para escoamento de matérias-primas e produtos finais, como a má qualidade das estradas vicinais que, aliado à falta de mão-de-obra e sua baixa qualificação, comprometem a competitividade da atividade.

A ocupação e implantação dos plantios de eucalipto, que é o principal produto silvicultural em MS, se deu de forma sem planejamento e com manejo inadequado, com o procedimento inicial de retirada a vegetação nativa para dar lugar ao eucalipto. O desmatamento não era necessário, uma vez que o plantio poderia ter sido feito numa combinação entre o Cerrado e a floresta plantada, ou ocupar áreas de antigas pastagens e lavouras cujo solo esteja degradado (FIDELIS \& LIMA, 2010).

Uma série de fatores influenciaram na determinação do nível de impactos ambientais com a implantação das florestas de eucalipto. A não observância das circunstâncias (Quadro 1) poderá causar impactos significativos na biodiversidade do Cerrado, principalmente se as áreas com florestas nativas forem substituídas por áreas de monocultura com espécies exóticas.

\begin{tabular}{|c|c|}
\hline Circunstâncias & Considerações \\
\hline $\begin{array}{c}\text { As condições prévias } \\
\text { ao plantio }\end{array}$ & $\begin{array}{l}\text { De fato, plantios desenvolvidos em áreas degradadas, com solos de } \\
\text { baixa fertilidade, na presença de erosão ou em áreas de pastagens, } \\
\text { por exemplo, geram impactos positivos sobre diversas variáveis } \\
\text { ambientais, a saber: elevação da fertilidade do solo (oriunda da } \\
\text { queda das folhas, matéria orgânica, sobre o solo), redução do pro- } \\
\text { cesso erosivo e aumento da biodiversidade (existem mais espécies } \\
\text { de flora e fauna em florestas de eucalipto do que em pastagens } \\
\text { ou em monocultivos de cana-de-açúcar ou soja, por exemplo). }\end{array}$ \\
\hline $\begin{array}{l}\text { O regime hídrico da } \\
\text { região }\end{array}$ & $\begin{array}{l}\text { Apenas em regiões de pouca chuva, abaixo de uma faixa de } 400 \\
\mathrm{~mm} / \mathrm{ano} \text {, o eucalipto poderia acarretar ressecamento do solo. Ou } \\
\text { seja, os impactos sobre lençóis freáticos, pequenos cursos d'água } \\
\text { e bacias hidrográficas dependem da região em que se insere a } \\
\text { plantação (e também da distância entre as plantações e a bacia } \\
\text { hidrográfica e da profundidade do lençol freático). }\end{array}$ \\
\hline
\end{tabular}

Continua... 


\begin{tabular}{|c|c|}
\hline $\begin{array}{l}\text { O bioma de inserção } \\
\text { da atividade silvi- } \\
\text { cultural }\end{array}$ & $\begin{array}{l}\text { Os impactos sobre a biodiversidade local também dependem } \\
\text { do bioma e da condição prévia da região onde a floresta será } \\
\text { implantada. Implantadas em áreas de florestas nativas, como as } \\
\text { de mata atlântica e cerrado, as plantações acarretam redução da } \\
\text { biodiversidade. Implantada, por outro lado, numa região de sava- } \\
\text { na, ou mesmo numa região que anteriormente era coberta com } \\
\text { mata atlântica, mas que foi desmatada, a floresta exótica acarreta } \\
\text { aumento da biodiversidade da flora e fauna locais. }\end{array}$ \\
\hline $\begin{array}{l}\text { As técnicas de ma- } \\
\text { nejo empregadas }\end{array}$ & $\begin{array}{l}\text { Diferentes técnicas de manejo podem acarretar impactos bastante } \\
\text { distintos. Se no momento da colheita, por exemplo, galhos, folhas } \\
\text { e cascas são deixados no local, parte dos nutrientes retirados pela } \\
\text { árvore é devolvida ao solo. A manutenção dessa matéria orgânica } \\
\text { auxilia também na redução do processo erosivo. }\end{array}$ \\
\hline $\begin{array}{l}\text { A integração da } \\
\text { população local }\end{array}$ & $\begin{array}{l}\text { A atividade silvicultural com eucaliptos não exclui do sítio onde é } \\
\text { realizada a possibilidade de outras formas consorciadas de pro- } \\
\text { dução. }\end{array}$ \\
\hline
\end{tabular}

Quadro 1: Circunstâncias a serem observadas para determinação de impacto ambiental em monoculturas de Eucalyptus spp.

Fonte: Adaptado de VITAL, 2007.

Desde o início da implantação dos grandes maciços florestais em MS, a mudança no uso e ocupação do solo causou impactos ambientais, econômicos e sociais importantes, sobretudo na região leste do estado, refletindo em mudanças na produção silvicultural. Neste contexto, é de fundamental importância demonstrar a dinâmica da produção silvicultural nos municípios de Três Lagoas, Água Clara e Ribas do Rio Pardo, localizados na região leste do estado de Mato Grosso do Sul, especificamente na microrregião de Três Lagoas.

\section{DELINEAMENTO EXPERIMENTAL}

\section{Região de Estudo}

A microrregião de Três Lagoas é uma das 11 microrregiões do estado de Mato Grosso do Sul. Pertencente à mesorregião do Leste, esta microrregião possui uma área total de aproximadamente $50.495 \mathrm{~km}^{2}$, representando cerca de $14 \%$ da extensão territorial do estado. Está dividida em cinco municípios: Três Lagoas, Água Clara, Ribas do Rio Pardo, Brasilândia e Santa Rita do Pardo.

Os dados apresentados e analisados neste estudo correspondem somente aos municípios de Três Lagoas, Água Clara e Ribas 
do Rio Pardo (Figura 1). Apesar dos municípios de Brasilândia e Santa Rita do Pardo também pertencerem à mesma microrregião, estes possuem menor área dedicada à produção silvicultural nos últimos anos (Tabela 1).

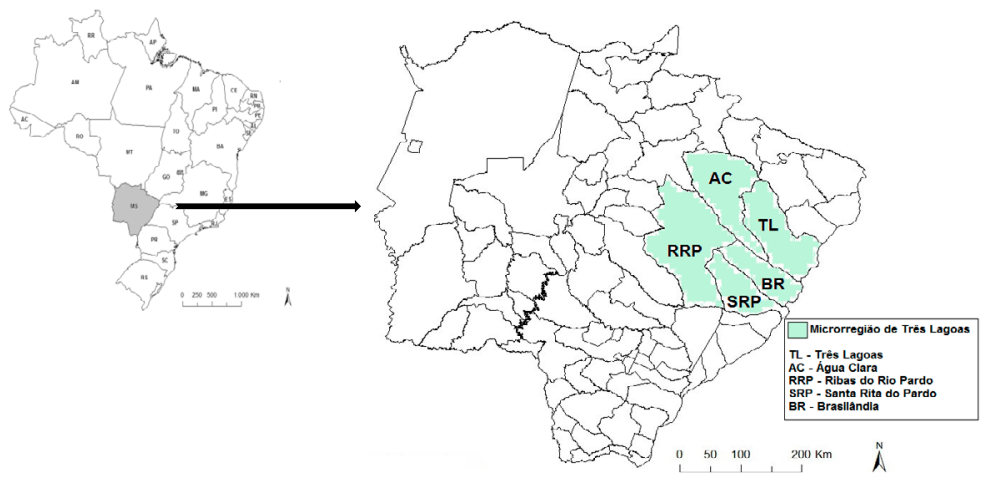

Figura 1. Localização da microrregião de Três Lagoas e os municípios de Três Lagoas (TL), Água Clara (AC), Ribas do Rio Pardo (RRP), Santa Rita do Pardo (SRP) e Brasilândia em Mato Grosso do Sul

Fonte: Adaptado a partir de base cartográfica do IBGE.

\begin{tabular}{cccc}
\hline Municípios & Área Total (ha) & \multicolumn{2}{c}{ Área Silvicultura (ha) } \\
& & $\mathbf{2 0 1 4}$ & $\mathbf{2 0 1 5}$ \\
\cline { 3 - 4 } Três Lagoas & 1.020 .695 & 200.200 & 217.700 \\
Ribas do Rio Pardo & 1.730 .881 & 180.000 & 200.800 \\
Água Clara & 780.921 & 118.500 & 120.400 \\
Brasilândia & 580.722 & 58.000 & 60.000 \\
Santa Rita do Pardo & 613.973 & 20.000 & 21.480 \\
\hline
\end{tabular}

Tabela 1: Área destinada à produção silvicultural na microrregião de Três Lagoas em 2014 e 2015

Fonte: Construção dos autores com dados primários do IBGE (2016).

Os municípios desta microrregião apresentam características geográficas comuns, como: clima tropical úmido com um a três meses secos (IBGE, 2002); temperatura média entre $21^{\circ}$ e $32^{\circ} \mathrm{C}$; variação de altimetria entre 70 e 320 metros; e índice pluviométrico variando de 1200 a $1500 \mathrm{~mm}$ por ano (INMET, 2017). 
O Produto Interno Bruto (PIB) dos três municípios, impulsionado pela silvicultura, vem apresentando crescimento nos últimos anos medidos, sendo possível perceber também o crescimento na participação de cada município no PIB total do estado (Quadro 2).

\begin{tabular}{ccccccc}
\hline Município & & \multicolumn{2}{c}{ PIB (mil reais) } & & \multicolumn{2}{c}{$\begin{array}{c}\text { Participação no PIB } \\
\text { Total MS (\%) }\end{array}$} \\
\hline & 2011 & 2012 & 2013 & 2014 & 2011 & 2014 \\
\hline Três Lagoas & 4.391 .832 & 5.050 .497 & 6.494 .386 & 7.204 .774 & $\mathbf{7 , 9 7}$ & $\mathbf{9 , 1 3}$ \\
\hline Água Clara & 345.724 & 428.894 & 467.016 & 517.205 & $\mathbf{0 , 6 3}$ & $\mathbf{0 , 6 6}$ \\
\hline $\begin{array}{c}\text { Ribas do } \\
\text { Rio Pardo }\end{array}$ & 443.083 & 550.693 & 594.452 & 667.568 & $\mathbf{0 , 8 0}$ & $\mathbf{0 , 8 5}$ \\
\hline
\end{tabular}

Quadro 2: Incremento do PIB dos municípios na microrregião de Três Lagoas no período de 2011 e 2014

Fonte: Construção dos autores com dados primários do IBGE (2016).

O bioma predominante na área de pesquisa é o Cerrado, mas também apresenta pequenas áreas remanescentes de Mata Atlântica (IBGE, 2004). Os tipos de solos mais comuns na região são os do tipo: Latossolo Vermelho Distrófico, e Argissolos Vermelho e Amarelo Distróficos (IBGE, 2003). Para Almeida et al. (2013), há predominância de solos classificados como Latossolo Vermelho e Neossolo Quartzarênico, com textura média e arenosa, topografia plana e suavemente ondulado, geralmente ácidos e com baixa fertilidade natural.

A principal via de acesso aos municípios a partir da capital Campo Grande é a rodovia BR-262, que também serve como principal rota de escoamento dos produtos da silvicultura e dá acesso ao estado de São Paulo, divisa com Três Lagoas.

\section{Metodologia}

Os dados apresentados foram obtidos de planilhas publicadas pelo Instituto Brasileiro de Geografia e Estatística (IBGE), na plataforma IBGE cidades, que disponibiliza dados sobre a extração vegetal e silvicultura de todos os municípios de Mato Grosso do Sul. O estudo teve como recorte a produção silvicultural de Três Lagoas, Água Clara e Ribas do Rio Pardo de 2011 a 2015, por serem os municípios com maior área dedicada à silvicultura na microrregião de Três Lagoas no período considerado. 


\section{RESULTADOS E DISCUSSÃO}

O estabelecimento dos maciços florestais na microrregião de Três Lagoas iniciou-se antes da criação do estado de Mato Grosso do Sul, que ocorreu a partir do desmembramento da parte sul do estado de Mato Grosso, regulamentado pela Lei Complementar № 31, de 11 de outubro de 1977. Segundo Pereira (2007), a implantação dos maciços na região tinha como objetivo inicial o fornecimento de madeira para as fábricas de celulose nas regiões sul e sudeste do país, atividade esta que foi incentivada por programas de florestamento como o Programa Nacional de Papel e Celulose do Governo Federal, implantado no início dos anos 1970 durante o governo militar.

Porém, uma série de fatores contribuiu para o insucesso dos projetos iniciais de florestamento na região, tais como a falta de manutenção técnica dos hortos florestais, os desvios de recursos financeiros, a falta de preocupações conservacionistas em relação aos recursos naturais, e a mão-de-obra (SILVA, 2002).

Com a crise do petróleo, principalmente no final da década de 1970, a produção de madeira na microrregião, que inicialmente seria destinada ao mercado interno, passou a ser impraticável devido ao encarecimento dos custos de transporte. Com isso, incentivos fiscais e subsídios do governo foram direcionados para promover a instalação de fábricas de papel e celulose na própria região. Porém, tais incentivos não foram suficientemente atrativos, levando a uma paralisação do programa de florestamento na época (Pereira, 2007; Martins, 1998). Com a indefinição quanto à destinação da madeira plantada, fatores como incêndios de grandes proporções, geadas ocasionais e ataque de formigas destruíam parte das plantações ou diminuíam sua produtividade, causando prejuízos econômicos, sociais e ambientais (SILVA, 2002).

Para solucionar o problema entre as empresas plantadoras de eucalipto, os proprietários de terra e as siderúrgicas de Minas Gerais - que são as maiores consumidoras de carvão vegetal do país - foi firmado um acordo em 1985 visando a mitigação de perdas econômicas. Com isso, um grande número de carvoarias instalou-se na microrregião de Três Lagoas, causando impactos socioambientais importantíssimos inerentes à atividade carvoeira (PEREIRA, 2007; MARTINS, 1998). 
Devido aos eventos históricos que levaram ao encarecimento da logística, a produção silvicultural em Ribas do Rio Pardo está concentrada na produção de carvão e lenha para serem usados como combustível (Figura 2 e 3). Pelas figuras apresentadas é possível perceber que a produção de carvão vegetal e de lenha é majoritariamente representada por este munícipio, que diferente dos demais municípios analisados, por estar localizado mais distante das indústrias de extração de celulose em Três Lagoas, acaba tendo custos mais elevados quando a destinação da sua produção é a indústria de papel e celulose.

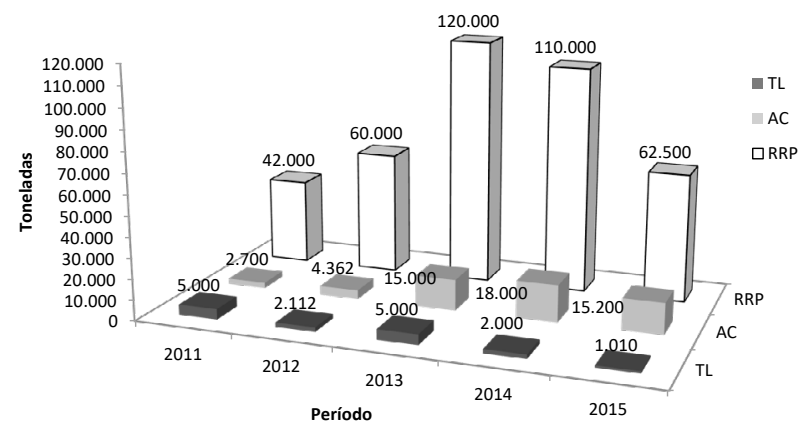

Figura 2. Produção de carvão vegetal nos municípios de Três Lagoas (TL), Água Clara (AC) e Ribas do Rio Pardo (RRP) de 2011 a 2015

Fonte: Elaborada com dados primários do IBGE (2016)

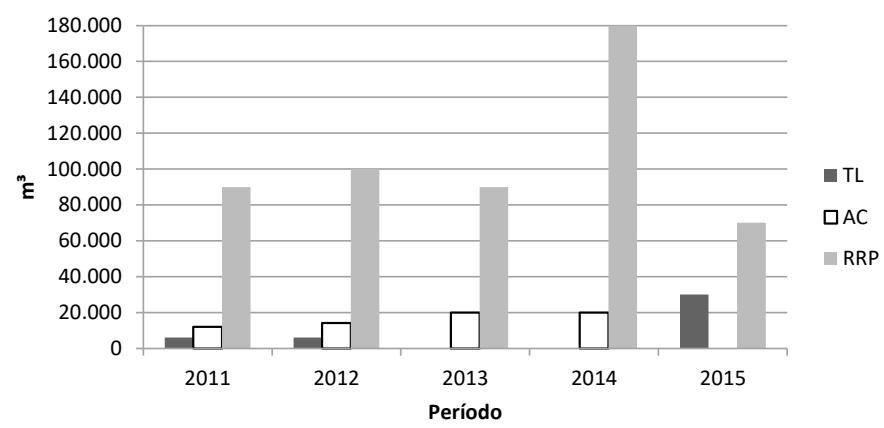

Figura 3. Produção de lenha nos municípios de Três Lagoas (TL), Água Clara (AC) e Ribas do Rio Pardo (RRP) de 2011 a 2015

Fonte: Elaborada com dados primários do IBGE (2016). 
Atualmente a produção de madeira de eucalipto no estado de Mato Grosso do Sul tem como principal destino o fornecimento de matéria-prima às indústrias de papel e celulose localizadas em Três Lagoas e em menor escala às serrarias, que processam a madeira para geração de lenha ou carvão que são absorvidos por siderúrgicas, processadoras de grãos e cerâmicas (ORTIGOZA \& SENNA, 2016).

A madeira em tora é o item mais produzido dentre os produtos da silvicultura na microrregião (Tabela 2), participando com uma média de $96 \%$ do total da produção silvicultural no período considerado.

\begin{tabular}{cccccc}
\hline Produtos da Silvicultura & $2011(\%)$ & $2012(\%)$ & $2013(\%)$ & $2014(\%)$ & $2015(\%)$ \\
\hline Carvão vegetal (ton.) & 1,07 & 1,45 & 2,31 & 2,00 & 1,01 \\
\hline Lenha (m $\left.{ }^{3}\right)$ & 2,55 & 3,35 & 1,66 & 2,75 & 1,27 \\
\hline Madeira em tora (m $\left.{ }^{3}\right)$ & 96,24 & 95,02 & 95,92 & 95,18 & 97,64 \\
\hline Eucalipto - folha (ton.) & 0,07 & 0,07 & 0,03 & 0,02 & 0,02 \\
\hline Resina (ton.) & 0,07 & 0,12 & 0,07 & 0,05 & 0,06 \\
\hline
\end{tabular}

Tabela 2. Produtos da silvicultura da microrregião de Três Lagoas e a relação porcentual do total produzido

Fonte: Elaborada com dados primários do IBGE (2016)

A produção de madeira em toras (Figura 4) é maior em Três Lagoas devido à proximidade com as indústrias de celulose instaladas no próprio município, que demandam madeira de eucalipto nesse formato para processamento.

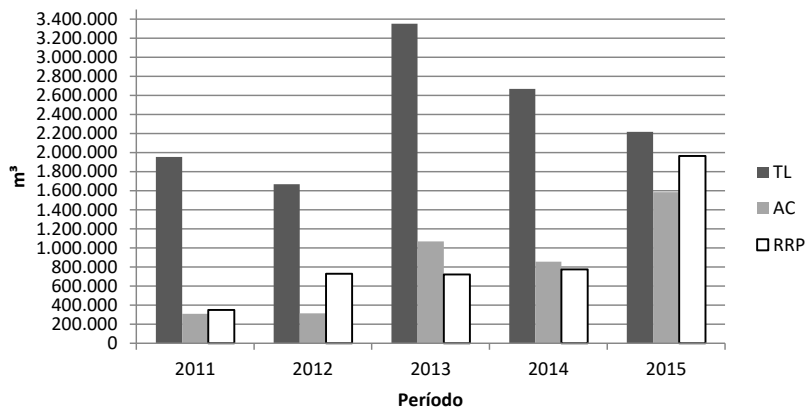

Figura 4. Produção de madeira em tora nos municípios de Três Lagoas (TL), Água Clara (AC) e Ribas do Rio Pardo (RRP) de 2011 a 2015

Fonte: IBGE cidades (2016) 
Desta produção de madeira em tora, praticamente a sua totalidade é destinada à extração de celulose para o setor industrial de papel, sendo apenas uma pequena porcentagem destinada para outros fins (Figura 5).

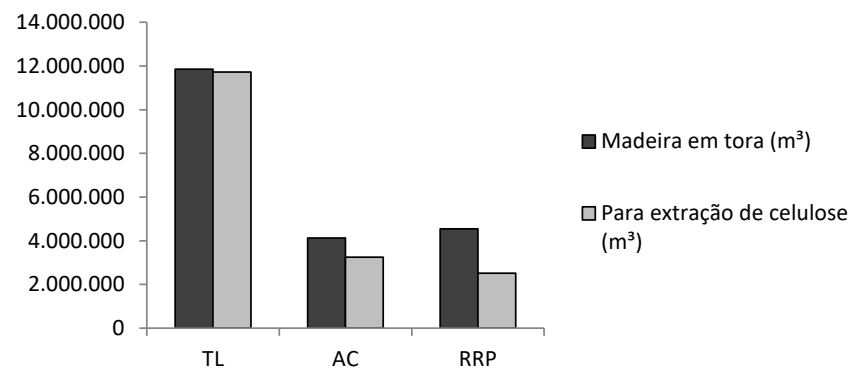

Figura 5. Comparação entre a produção total e a destinação da madeira em tora para extração de celulose nos municípios de Três Lagoas (TL), Água Clara (AC) e Ribas do Rio Pardo (RRP) de 2011 a 2015

Fonte: IBGE cidades (2016)

Em relação aos produtos não madeireiros provenientes da silvicultura, a produção de folhas de eucalipto para extração de óleos essenciais, por exemplo, teve sua produção diminuída. 0 município de Três Lagoas é o que tem a maior produção, porém, esta caiu de 3.167 toneladas em 2012 para 800 toneladas em 2015. Já em Água Clara, a maior produção foi de 800 toneladas em 2013, caindo para 756 toneladas em 2015. Em Ribas do Rio Pardo não há produção de folhas de eucalipto.

Para o produto resina - também conhecida como goma resina - a maior produção ocorre em Ribas do Rio Pardo devido a existência de maiores áreas plantadas com Pinus spp., de onde é extraída a resina. Segundo Antunes Junior (2016), após o processamento industrial da resina, os subprodutos gerados são usados como componentes de tintas, vernizes, colas, ceras, perfumaria, tintas de impressão, solventes, óleo de pinho, alcatrões, desinfetantes, desodorantes, reagentes químicos, dentre outros. A média de produção no período considerado no município foi de 4.129 toneladas. Em Três Lagoas não há produção de resina e em Água Clara, a maior produção foi de 1.020 toneladas em 2012 e em 2015 não houve produção. 
O sistema de produção silvicultural em Mato Grosso do Sul configura-se como um segmento produtivo de significativa importância socioeconômica, sobretudo se considerada a possibilidade desse setor gerar renda, empregos e promover o desenvolvimento do estado (ORTIGOZA \& SENNA, 2016).

\section{CONSIDERAÇÕES FINAIS}

O desenvolvimento da silvicultura em Mato Grosso do Sul, sobretudo na microrregião de Três Lagoas, onde ocorreu a maior expansão das áreas plantadas com eucalipto no período considerado, causou impactos em diversos setores. A atividade gera empregos diretos e indiretos em toda a cadeia produtiva, desde o plantio das mudas, passando pelas atividades de manejo, manutenção, beneficiamento e logística, até o consumidor final, seja na forma de produtos madeireiros ou não madeireiros.

Contudo, para que o setor florestal no estado desenvolva de forma sustentável, devem ser considerados não só os ganhos na economia, mas também os aspectos sociais e ambientais que estão diretamente relacionados às mudanças na dinâmica territorial e no uso e ocupação do solo.

Portanto, a sustentabilidade do setor deve estar alicerçada não só em políticas de concessões de créditos e incentivos fiscais a grandes empreendimentos, mas também na fiscalização para cumprimento das leis ambientais, das condições de trabalho, principalmente nas carvoarias, de planejamento urbano, garantia de acesso aos serviços públicos essenciais à população e investimento na educação para formação de mão-de-obra qualificada.

É importante ressaltar a importância de outros estudos que continuem avaliando e aprofundando a temática, especialmente no que se refere aos impactos sociais e ambientais que a atividade possa causar a médio-longo prazo, gerando informações que auxiliem os gestores na elaboração de políticas públicas que promovam qualidade de vida, uso racional dos recursos naturais e crescimento econômico. 


\section{REFERÊNCIAS}

ABRAF - Associação Brasileira de Produtores de Florestas Plantadas. Anuário estatístico 2013 ano base 2012. Brasília, 2013.

CHAEBO, G.; CAMPEÃO, P.; KODAMA, A. K.; SANTOS, A.B.; NORILLER, R. M. Silvicultura em Mato Grosso do Sul: desafios e perspectivas a formulação de um arranjo produtivo local. Sociedade Brasileira de Economia, Administração e Sociologia Rural. UFMS, Campo Grande, 2010.

FAGUNDES, M. B. B.; SCHMIDT, V. Competitividade do SAG da Silvicultura no Mato Grosso do Sul: um enfoque sobre as florestas plantadas de eucalipto. Revista de Economia e Agronegócio, v. 9, n. 2, p. 253-274, 2011.

FIDELIS, A. C.; LIMA, J. D. Impactos Ambientais da Silvicultura no Bioma Cerrado. Universidade Federal de Goiás - Campus Catalão, 2010. Disponível em: <https:// goo.gl/Nw7yLb>. Acesso em: 12/07/2017.

FONSECA, S. R.; THOMAZ JUNIOR, A. A consolidação do complexo de celulose e papel na região leste de Mato Grosso do Sul: Estudo de caso do município de Selvíria. Revista Eletrônica da Associação dos Geógrafos Brasileiros - Seção Três Lagoas/MS - n. 19, p. 75-103, 2014.

IBGE - Instituto Brasileiro de Geografia e Estatística. Extração Vegetal e Silvicultura, IBGE cidades, 2016. Disponível em: <http://cod.ibge.gov.br/9E6>. Acesso em: 22/07/2017.

. Mapa de clima do Brasil. Rio de Janeiro, 2002. Disponível em: <https:// goo.gl/RYmdBR>. Acesso em: 01/08/2017.

. Mapa de solos do Brasil. Rio de Janeiro, 2003. Disponível em: <https:// goo.gl/eq8rwK>. Acesso em: 20/07/2017.

. Mapa de biomas e de vegetação, 2004. Disponível em: <https://goo.gl/ ntXsPo>. Acesso em: 21/07/2017.

INMET - Instituto Nacional de Meteorologia. Disponível em: < https://goo.gl/ XiqKno>. Acesso em: 02/08/2017.

MARTINS, S. R. O. A dinâmica do lugar no contexto do trabalho degradante: o caso das carvoarias em Ribas do Rio Pardo - MS. Revista Multitemas, n.8, p. 79-96, 1998.

MATO GROSSO DO SUL. Plano Estadual para o Desenvolvimento Sustentável de Florestas Plantadas. Campo Grande, 2009.

MOSCA, A. A. O. Avaliação dos impactos ambientais de plantações de eucalipto no Cerrado com base na análise comparativa do ciclo hidrológico e da sustentabilidade da paisagem em duas bacias de segunda ordem. Tese (Doutorado em Geografia Física). Faculdade de Filosofia, Letras e Ciências Humanas. Universidade de São Paulo, São Paulo, 2008.

ORTIGOZA, F. S. S.; SENNA, R. J. Caracterização do segmento de florestas plan- 
tadas de eucalipto em Mato Grosso do Sul. Revista de Política Agrícola, Ano XXV, n. 2, p. 75-89, 2016.

PEREIRA, A. Os desafios para o trabalho nas carvoarias de Ribas do Rio Pardo

- MS. Dissertação (Mestrado em Geografia). Faculdade de Ciências e Tecnologia. Universidade Estadual Paulista. Presidente Prudente, 2007. $150 \mathrm{f}$.

REFLORE-MS. Informativo da Associação Sul-Mato-Grossense de Produtores e Consumidores de Florestas Plantadas. Campo Grande, 2013. Disponível em: <https://goo.gl/3Hbq4i>. Acesso em: 17/07/2017.

SILVA, E. A. O processo produtivo do carvão vegetal: um estudo em Mato Grosso do Sul. Tese (Doutorado em Geografia). Faculdade de Ciências e Tecnologia. Universidade Estadual Paulista. Presidente Prudente, 2002. $341 \mathrm{f}$.

SNIF - Sistema Nacional de Informações Florestais. Disponível em: < $\underline{\text { https://goo. }}$ gl/Zzk289 >. Acesso em: 26/07/2017.

VITAL, M. H. F. Impacto Ambiental de Florestas de Eucalipto. Revista do BNDES, Rio de Janeiro, v. 14, n. 28, p. 235-276, 2007. 